\title{
Phoma sp. (sect. Peyronellaea), como Agente Etiológico de Mancha Foliar de Paspalum atratum no Brasil
}

\author{
José R. N. Anjos', Maria J. A. Charchar ${ }^{1}$, Sérgio S. N. Anjos ${ }^{2} \&$ Rogério N. Teixeira $^{3}$ \\ ${ }^{1}$ Centro de Pesquisa Agropecuária dos Cerrados, Empresa Brasileira de Pesquisa Agropecuária, Cx. Postal 08223, \\ CEP 73301-970, Planaltina, DF, e-mail: ribamar@cpac.embrapa.br; ${ }^{2}$ Faculdade de Ciências da Saúde, Ciências \\ Farmacêuticas, Universidade de Brasília, CEP 70910-900, Brasília, DF; ${ }^{3}$ Embrapa Transferência de Tecnologia, \\ Cx. Postal 06840, CEP 71701-970, Brasília, DF
}

(Aceito para publicação em 23/05/2004)

Autor para correspondência: José Ribamar N. Anjos

ANJOS, J.R.N., CHARCHAR, M.J.A., ANJOS, S.S.N. \& TEIXEIRA, R.N. Phoma sp. (sect. Peyronellaea), como agente etiológico de mancha foliar de Paspalum atratum no Brasil. Fitopatologia Brasileira 30:72-74. 2005.

\section{RESUMO}

Phoma sp. (sect. Peyronellaea) foi consistentemente isolado de plantas de Paspalum atratum cv. Pojuca (capim Pojuca) com sintomas de manchas foliares em uma população no Distrito Federal, em 2002. Os conídios mostraram-se hialinos, predominantemente elípticos, unicelulares, gutulados, medindo entre 2,50-5,25 $\mu \mathrm{m}$ de largura e 10,25-17,25 $\mu \mathrm{m}$ de comprimento. Os picnídios mostraram-se escuros, medindo entre 100-310 $\mu \mathrm{m}$ de diâmetro, com pescoço curto, na maioria são globosos e solitários. Clamidósporos multicelulares, freqüentemente semelhantes a conídios de Alternaria foram observados nas colônias. Testes de patogenicidade em casa de vegetação e o ubsequente reisolamento do fungo confirmaram a hipótese de que Phoma sp. é o agente etiológico das manchas foliares de capim Pojuca. Os primeiros sintomas apareceram em todas as plântulas inoculadas, quatro a cinco dias após a inoculação. Sete outras espécies de gramíneas foram suscetíveis ao fungo. A ocorrência de manchas foliares de capim Pojuca causadas por Phoma sp. é relatada pela primeira vez no Brasil.

Palavras-chave adicionais: Phoma sect. Peyronellaea, patogenicidade, gramínea forrageira, semente.

\begin{abstract}
Phoma sp. (sect. Peyronellaea), as causal agent of leaf spot on Paspalum atratum in Brazil

The fungus Phoma sp. (sect. Peyronellaea) was consistently isolated from infected Paspalum atratum cv. Pojuca (Pojuca grass) plants with leaf spot symptoms in the Federal District, Brazil, in 2002. Conidia were hyaline, usually ellyptical, unicellular, gutullate, 2,50-5,25 x 10,25-17,25 $\mu \mathrm{m}$. Pycnidia were mostly solitary, 100-310 $\mu \mathrm{m}$ diameter, globose, usually with a short neck. Multicellular chlamidospores often resembling conidia of Alternaria were present in the colonies. Pathogenicity tests under greenhouse conditions and subsequent reisolations of Phoma sp. from artificially inoculated Pojuca seedlings confirmed the hypothesis that this fungus was the causal agent of the disease. Symptoms of leaf spot appeared four to five days after inoculation in $100 \%$ of the inoculated Pojuca grass plants. All seven species of grasses evaluated were susceptible to this fungus. The occurrence of leaf spots of Pojuca grass caused by Phoma sp. is reported for the first time in Brazil.
\end{abstract}

Additional keywords: Phoma sect. Peyronellaea, patogenicity, grass plant, seed.

O capim Pojuca é uma cultivar de Paspalum atratum Swallen coletado no município de Terenos, Mato Grosso do Sul (Leite et al., 2001), lançado sob a responsabilidade da Embrapa Cerrados, em 1999. É uma gramínea perene, adaptada a solos ácidos e de baixa fertilidade, indicada para áreas úmidas de baixadas sujeitas a alagamento temporário, ou mesmo para localidades com altas precipitações pluviométricas (Leite \& Fernandes, 1999). No entanto, ele tem bom desempenho também na pré-Amazônia e nas regiões Norte, Central e Sul do Cerrado (Anônimo, 2000; Karia \& Andrade, 2001). Suas características de alta produção de forragem, boa aceitação pelos bovinos e eqüinos e boa resistência ao ataque da cigarrinha-das-pastagens (Deois flavopicta Stal) (Anônimo, 2000), entre outras, fazem com que o capim Pojuca seja boa alternativa a outras gramíneas forrageiras. Até o momento, não há informações publicadas sobre a ocorrência de fitopatógenos causando manchas foliares nessa forrageira em condições naturais no Brasil.

Os objetivos desse trabalho foram caracterizar um isolado de Phoma sp. causando manchas foliares em capim pojuca em condições naturais no Distrito Federal, avaliar sua patogenicidade em plântulas de Pojuca e outras gramíneas.

Em abril de 2002, foram observadas manchas foliares severas em uma população de Pojuca com aproximadamente um ano de idade, em um experimento sobre produção de sementes de forrageiras, no Campo Experimental da Embrapa Transferência de Tecnologia, Fazenda Sucupira, Gama, DF. Os sintomas consistiam de manchas foliares necróticas variando de elípticas a alongadas, de coloração marrom (Figura 1-A). O isolamento do agente etiológico foi efetuado, 
Phoma sp. (sect. Peyronellaea), como agente etiológico de...

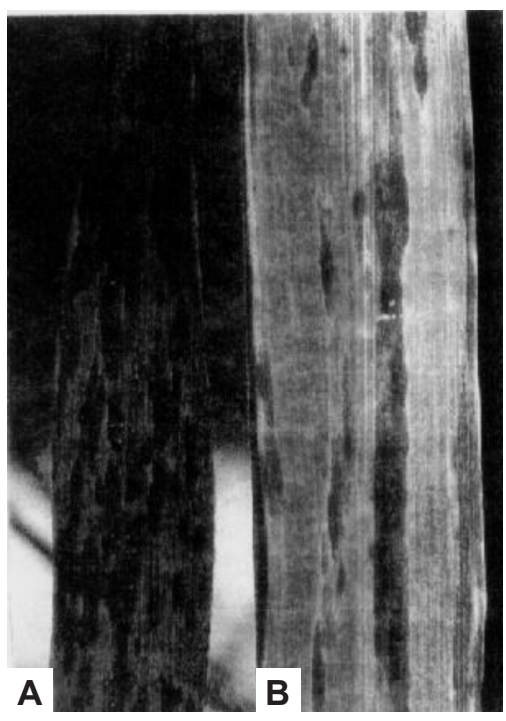

FIG. 1 - Sintomas de manchas foliares em Paspalum atratum cv. Pojuca induzidas por Phoma sp. A) Sintomas em condições de campo. B) Sintomas após inoculação artificial com Phoma sp. pelo método de pulverização com suspensão de conídios.

utilizando-se o método indireto, com a esterilização superficial de fragmentos de folhas necrosadas em $\mathrm{NaClO}$ a $1 \%$ e, incubados em BDA + estreptomicina. Culturas monospóricas de Phoma sp. provenientes desse isolamento foram remetidas para o CABI Bioscience, em Egham, Surrey, Reino Unido, onde foi identificado pelo Dr. G. Kinsey como Phoma sect. Peyronellaea (Goid. ex Togliani) Boerema (IMI 389269). As colônias do fungo em BDA eram inicialmente brancas com abundante micélio, tornando-se acinzentadas após cinco a seis dias de incubação a $25 \pm 1^{\circ} \mathrm{C}$, sob luz branca constante. $\mathrm{O}$ verso era de coloração acinzentada a escura. Em condições de campo (Figura 1-A), nas folhas com manchas causadas por Phoma sp., freqüentemente foram encontradas lesões causadas por Bipolaris maydis (Nisik. \& Myiake) Shoemaker.

Os conídios são hialinos, unicelulares, predominantemente elípticos, gutulados com uma a cinco diminutas gotas, mas 30\% são bigutulados com uma gota em cada extremidade.

TABELA 1 - Incidência de mancha foliar de Phoma spp. em gramíneas inoculadas com o isolado obtido de $P$. atratum cv. Pojuca

\begin{tabular}{lc}
\hline \hline Espécie & P.inoc./P.sint. \\
\hline Milho (Zea mays L.) cv. BR 106 & $20 / 20$ \\
Arroz (Oryza sativa L.) Primavera & $25 / 8$ \\
Cevada (Hordeum vulgare L.) AF 9585 & $20 / 5$ \\
Capim Vencedor (Panicum maximum Jacq.) cv. Vencedor & $20 / 5$ \\
Milheto [Pennisetum glaucum (L.) R.Br.] cv.BN 2 & $20 / 12$ \\
Capim Brachiaria (Brachiaria decumbens Stapf) cv. Brasilisk & $29 / 25$ \\
Trigo (Triticum aestivum L.) cv. Embrapa 22 & $31 / 13$ \\
Capim Tanzânia (P. Maximum Jacq.) cv. Tanzânia & $28 / 13$ \\
Capim Pojuca (Paspalum atratum Swallen) cv. Pojuca & $25 / 22$ \\
\hline 'P.inoc.-plantas inoculadas; P.sint.-plantas com sintomas.
\end{tabular}

${ }^{1}$ P.inoc.-plantas inoculadas; P.sint.-plantas com sintomas.
Em 100 conídios medidos em uma lâmina semi-permanente com lactofenol, as dimensões variaram de 2,50-5,25 $\mu \mathrm{m}$ de largura e 10,25-17,75 $\mu \mathrm{m}$ de comprimento. Os conídios desse isolado, portanto, são grandes comparativamente às espécies da seção Peyronellaea (Boerema, 1993; Boerema, 1997). Entretanto, há diversas espécies em fase de reavaliação, algumas das quais podem corresponder ao fungo em estudo. Os picnídios são escuros, medindo entre 100-310 $\mu \mathrm{m}$ de diâmetro, na maioria, globosos, solitários e com pescoço curto. As colônias produziram clamidósporos multicelulares freqüentemente semelhantes a conídios de Alternaria spp.

Para confirmar a patogenicidade desse isolado, plântulas de $P$. atratum cv. Pojuca foram inoculadas usando micélio e esporos de uma cultura monospórica, multiplicada em BDA durante seis dias, maceradas em água destilada estéril, ajustada à concentração de 1 x $10^{5}$ esporos $/ \mathrm{ml}$. A suspensão do inóculo foi pulverizada com atomizador manual em folhas de 20 plântulas, sem ferimento. Para manter a umidade após a inoculação, as mudas foram cobertas com sacos plásticos e mantidas em bandejas com água dentro de uma câmara de incubação a $25^{\circ} \mathrm{C}$, durante $72 \mathrm{~h}$. Vinte mudas sadias, submetidas às mesmas condições, mas não inoculadas, serviram como testemunhas. Em seguida, as mudas foram transferidas para uma casa de vegetação. Os primeiros sintomas de manchas foliares apareceram em todas as plântulas inoculadas, quatro a cinco dias após a inoculação. As lesões novas mostraram-se pequenas e elípticas, coalescendo, mais tarde, e se tornando alongadas e necróticas, irregulares, e de coloração marrom (Figura 1-B). As plântulas testemunhas permaneceram assintomáticas. Com o reisolamento de Phoma sp. atenderam-se os requisitos dos postulados de Koch, confirmando-se assim a hipótese de que esse fungo é o agente causal das manchas foliares de capim Pojuca.

Sete espécies de gramíneas, das quais duas cultivares de Panicum maximum Jacq., foram inoculadas com o isolado de Phoma spp. em estudo, utilizando-se do mesmo método de inoculação. Todas as espécies testadas mostraram sintomas (Tabela 1) de manchas foliares alongadas, necróticas e irregulares, quatro a cinco dias após a inoculação. A severidade variou de medianamente severa em arroz (Oryza sativa L.), cevada (Hordeum vulgare L.), P. maximum cv. Vencedor, trigo (Triticum aestivum L.) e P. maximum cv. Tanzânia a altamente severas em Brachiaria decumbens cv. Brasilisk, milho (Zea mays L.) e capim Pojuca, que foi avaliado como controle positivo, servindo assim como comparação para as demais espécies.

Para avaliar a associação de Phoma sp. com sementes de Pojuca, 400 sementes de um lote colhido em 2002, no mesmo campo onde foi verificada a presença de lesões foliares, foram esterilizadas superficialmente com $\mathrm{NaOCl}$ a $1 \%$ durante 5 min. Em seguida, foram lavadas com água estéril e incubadas em placas de Petri com BDA a $25 \pm 1{ }^{\circ} \mathrm{C}$, durante quatro dias em regime constante de luz branca. Verificou-se a presença de Phoma spp. em 12 sementes (3\%), cuja patogenicidade foi demonstrada em Pojuca seguindo metodologia idêntica à 
utilizada para o isolado da parte aérea. Este é o primeiro relato da ocorrência de mancha foliar de Phoma em P. atratum cv. Pojuca no Brasil.

\section{REFERÊNCIAS BIBLIOGRÁFICAS}

ANÔNIMO. Capim Pojuca (Paspalum atratum), capim nativo alta produção e qualidade. Folder, Embrapa Cerrados, Brasília, 2000.

BOEREMA, G.H. Contributions towards a monograph of Phoma (Coelomycetes) - II Section Peyronellaea. Persoonia 15:197-221. 1993.

BOEREMA, G.H. Contributions towards a monograph of Phoma
(Coelomycetes)-V. Subdivision of the genus in sections. Mycotaxon 64:321-333. 1997.

KARIA, C.T. \& ANDRADE, R.P. Cultivo do Capim Pojuca. Recomendação Técnica ${ }^{\circ} 50$, Embrapa Cerrados, Brasília, 2001.

LEITE, G.G. \& FERNANDES, F.D. Qualidade da forragem do capim Paspalum atratum cv. Pojuca. Comunicado Técnico ${ }^{\circ}$ 9, Embrapa Cerrados, Brasília, 1999.

LEITE, G.G., SILVEIRA, L.F., FERNANDES, F.D. \& GOMES, AC. Crescimento e composição química do capim Paspalum atratum cv. Pojuca. Boletim de Pesquisa e Desenvolvimento ${ }^{\circ} 19$, Embrapa Cerrados, Brasília, 2001. 